\title{
Hydrological education and training needs in sub-Saharan Africa: requirements, constraints and progress
}

\author{
D. A. Hughes \\ Institute for Water Research, Rhodes University, Grahamstown, South Africa \\ Correspondence to: D. A. Hughes (d.hughes@ru.ac.za) \\ Received: 14 November 2011 - Published in Hydrol. Earth Syst. Sci. Discuss.: 5 December 2011 \\ Revised: 17 February 2012 - Accepted: 27 February 2012 - Published: 19 March 2012
}

\begin{abstract}
This paper represents a perspective on the education and training needs related to hydrology and water resources science within the sub-Saharan Africa region and discusses the requirements of the region, some of the relatively recent developments and initiatives and some of the constraints that exist and remain difficult to surmount. The requirements include the development of academic research capacity and technical skill for both the private and public sector at a variety of levels. Some of the constraints that exist include a lack of adequate funding, lack of follow-up after short training courses, lack of institutional support to continue training, and competition for major water resources development projects from organizations outside the region. One of the main conclusions is that to sustain both educational and practical expertise in hydrology and water resources science within the region there is a need to build a "critical mass" of local expertise. Part of this could be achieved by increasing networking within the region and promoting the sharing of information, tools and expertise. There is also a need to promote institutional support.
\end{abstract}

\section{Introduction}

There have been a number of relatively recent publications that have questioned the way in which hydrologists are educated within the various educational institutions around the world (Nash et al., 1990; Salz, 1996; Wagener et al., 2007, 2010). Most of these publications refer to the diverse disciplinary backgrounds from which hydrologists originate, as well as the diversity of problems that need to be solved if hydrologists are to contribute to improved management of water resources. While hydrology is recognized by most as a geoscience, it has been dominated in the past by contributions from hydrologists who have a background in civil engineering (Muzik, 1996) and has been largely driven by the need to solve engineering problems. It is becoming increasingly evident that the demands on hydrologists are changing as they are required to understand the complexities of the global water system within an interdisciplinary framework (Wagener et al., 2007), but continue to develop their own discipline as a science (through improved conceptual understanding) and for applications in practice (through improved prediction methods). Some of the identified problems are related to diversity in the teaching and training material that is used and a lack of consistency that could be hindering the advance of hydrology as a science (Wagener et al., 2007). The dichotomy of the development of hydrology as a science and its practice, as either an applied science or an engineering sub-discipline, is also seen as limiting the application of research results in practice (Nash et al., 1990). Most of the background material that was used for these publications appears to have been derived from educational institutions in the developed world which generally have access to adequate resources in terms of educators (lecturers and post-graduate supervisors), text books and journals, as well as computer and laboratory facilities. Hence the focus is on the development of curricula, appropriate teaching material and instructor awareness of emerging trends in hydrological science. There are many educational facilities in the developing world where access to such facilities cannot be taken for granted and where there are additional challenges associated with creating an enabling environment for educating the future generation of hydrological researchers or practitioners.

There can be little doubt that the future economic and social development of sub-Saharan Africa relies to a large extent upon the sustainable management of the water resources of the sub-continent (Grey and Sadoff, 2002). Chapter 3 in the Africa Water Atlas (UNEP, 2010) refers to 9 "Water Challenges and Opportunities" which includes such issues as access to safe drinking water and sanitation, water for food security and managing water under potential threats related to global climate change. The final challenge referred to is "enhance capacity to address water challenges" and is 
premised on the lack of existing institutional, financial and human capacities for managing water. The chapter refers to the main constraints as an "insufficient knowledge base", no "effective research and technology base" and "weak institutional arrangements" for the "allocation and management of water".

The author accepts that there are many challenges to developing the hydrological education and research base in Africa, but does not entirely agree with the UNEP (2010) report that there is no research or technology base. Recent personal experiences have also suggested that there is a large potential knowledge base that needs to be encouraged and better organized so that it can make a greater contribution to water management in the region and the science of hydrology internationally. The paper therefore attempts to look at some of the hydrological education and training requirements for subSaharan Africa (which will overlap with those from other parts of the world), together with the constraints and some recent progress that has been made. The main focus of the paper is on post-graduate education and training (the main experience base of the author), while it is recognized that undergraduate training needs cannot be ignored.

\section{Hydrological issues in sub-Saharan Africa}

Many of the issues related to the approaches that can be used for hydrological analyses and water resources estimation in sub-Saharan Africa are different to some other parts of the world. This is largely because of the high variability in space and time that occurs across the region coupled with the general scarcity of hydrological observations and data (Hughes, 2006) and poorly quantified human impacts in terms of abstractions and land use change. Arguably, this is one of the areas of the world where the concepts of uncertainty analysis (Pappenberger and Beven, 2006) need to be fully embraced as part of both hydrological research (Hughes et al., 2010) and water resources management practice. A great deal of uncertainty has always existed in almost all of the hydrological estimates that have been used for designing water resource schemes, or making decisions about allocations for different users and for sustaining the natural ecological functioning of water bodies (rivers, wetlands, estuaries, etc.). However, there do not seem to be very many examples in the region where the concepts have been applied as part of research, and even fewer where decisions have been taken with uncertainty explicitly accounted for. The potential impacts of global change (Andersson, 2006; Lumsden et al., 2009) and the expanding population (together with the related water supply and food security concerns) of the region adds further impetus to the necessity of accounting for uncertainties in the future (Vörösmarty et al., 2000).

It is apparent therefore that the training requirements (see next section for further details) of the future generation of water scientists, engineers and decision makers, worldwide, should include the principles and methods of making uncertain hydrological estimates and how to deal with them in engineering design and water resources management decision making. This will almost certainly require a paradigm shift in the design of teaching, training and research methods and material. Wagener et al. (2010) summarise the key components of the required paradigm shift, but the question remains about how this can be achieved in poorly-resourced regions such as sub-Saharan Africa. These regions may have to rely initially on the development of the required approaches and materials from countries with greater research and educational experience and resources (e.g. Yadav, 2007). However, they will also have to be adapted to the local conditions and applied within the sub-Saharan Africa regional context (e.g. Kapangaziwiri et al., 2009). The issue of paradigm shifts in hydrological research raises one of the key questions about training and research development in sub-Saharan Africa. Should the focus be primarily on the application of scientific methods, developed in the past or outside the region, to water resources management problems that exist within the region? The alternative is to strive for a better balance and to encourage innovative scientific developments from within the region.

\section{Training requirements}

The background to the training requirements in sub-Saharan Africa lies in the many water related problems that are experienced within the region coupled with a small pool of qualified scientists and engineers and a relatively small academic community reliant upon a limited number of experienced staff. The first issue that needs to be considered is associated with aligning the training requirements with the needs of the region. There is no doubt that the sustainable management of water in sub-Saharan Africa requires multi- and interdisciplinary approaches that include specialist input from a number of natural sciences, engineering, economics and the social and political sciences. While it may be argued that one of the failings of the past has been the inability of single disciplines to come together in a truly multi-disciplinary manner, it should not be imagined that this can be achieved at the expense of adequate training in the individual disciplines. As noted by Metzger and Zare (1999) "strong interdisciplinary programs can only be built in circumstances in which strong disciplinary programs already exist. It makes no sense to sacrifice successful disciplinary efforts to appease perceived interdisciplinary needs".

From the perspective of the hydrological sciences, it is necessary to be quite clear in distinguishing between the training requirements of hydrologists (as scientists), water engineers and water resources managers (Kirshen et al., 2004), despite the fact that they will contain overlapping components. The author contends that there has been insufficient clarity in this distinction in the past and that the label 
"hydrologist" has been used too loosely and largely at the expense of hydrology as a science. This is not a situation that is unique to sub-Saharan Africa (Nash et al., 1990), but perhaps the impacts have been felt more strongly in this developing region because of the relatively small community of educators and practitioners as well as a strong (and probably justifiable) emphasis on practical solutions. There is little doubt that the region needs expertise in all of the individual disciplines that contribute to integrated water resources management (IWRM). It is also desirable for the training to include the broader context of IWRM and the contribution that the individual disciplines can make to complex multidisciplinary solutions.

A further issue related to training requirements is establishing a balance between academic and practical training, an issue that might also be referred to as the difference between a science-based approach versus a more engineering application approach. The emphasis in the region over the last few decades has almost certainly been on the engineering approach, partly because many of the students who have studied hydrology have been enrolled in engineering departments. More recently there has been a shift toward a more science-based approach in some university departments where there are sufficient resources. The region certainly requires expertise in the practical application of hydrological and water resources analysis methods and this may be considered to be justification for focusing on the engineering approach to training. However, there are two additional factors that have to be considered. The first is that without a sound scientific background to the various practical analysis methods (including hydrological models), users are at a disadvantage when it comes to their application in "difficult" situations, such as many of the completely ungauged catchments that exist throughout the region. Getting the right results for the right reasons (Kirchner, 2006) has often been neglected in practical hydrological modelling, partly because the right reasons are often not known in data scarce areas. A greater scientific, rather than mathematical, focus (Hughes, 2010) on modelling might go a long way towards solving these issues. The second is that if the training does not include the scientific basis for the methods it will always be difficult to create a new generation of researchers who can develop new and improved methods, as well as train the following generation of both scientists and engineers. Within South Africa this is already being experienced with relatively few young recruits to teaching and research groups within universities and a rapidly aging cadre of experienced staff. However, this problem is also related to the limited career (small number of available posts) and remuneration prospects of academics in the region (referred to in more detail below).

\section{Existing resources}

There are relatively few universities within southern Africa that offer either undergraduate or post-graduate training in hydrology and water resources science (Fig. 1). Many of these include hydrology as only a relatively small component of courses in other primary disciplines (e.g. civil engineering, geography or environmental science). As far as the author is aware there are only 3 universities where hydrology is taught at undergraduate level as a primary discipline and all of these are located within South Africa. At the MSc level there are a number of course-work degrees offered, but many of these are orientated towards water resources management and less towards the scientific aspects of hydrology, or more generally, water resources science. From a regional perspective, the courses offered through WaterNet (http://www.waternetonline.ihe.nl - Jonker et al., 2012) are an excellent example of regional cooperation by many different institutions and include water resources management and science-based training (Wright et al., 2001).

Some of the universities within the region offer opportunities for research-based MSc and $\mathrm{PhD}$ degree training, but are constrained by funding for student bursaries and a relatively small number of qualified and experienced project supervisors. Recent experiences suggest that the pool of potential post-graduate students is far greater than the existing capacity (in terms of financial and/or supervisory support). Between 2008 and 2010 there were two calls for applications for post-graduate opportunities in the SSAWRN (Sub-Saharan Africa Water Resources Network) project, a part of the Carnegie Foundation of New York funded RISE (Regional Initiative in Science Education) programme (http: //sig.ias.edu/rise). The two calls offered 26 opportunities for post-graduate research at the MSc or PhD level. A total of 187 applications were received and the vast majority of these were qualified to enter one of the four universities (Rhodes in South Africa, Makerere in Uganda, Okavango Research Institute in Botswana and Eduardo Mondlane in Mozambique - Fig. 1) that form part of SSAWRN. A more detailed examination of the backgrounds, educational qualifications and proposed research topics provided more evidence to support the contention that most of the training offered in the region is on water resources management, rather than water resources science. Relatively few of the students proposed projects that could be considered to be scientific development research (19\% in hydrology and 17\% in aquatic ecology), while many more proposals $(64 \%)$ were related to the application of existing methods to solve specific water resources problems.

Apart from the university institutions that are currently recognized as having some resources and are therefore offering some form of post-graduate training, there are others where the potential exists, if some of the constraints can be over-come. Kyambogo University is situated in Kampala, Uganda (close to the better known and better resourced 


\begin{tabular}{|ll|}
\hline Symbol & University \\
\hline EMU & Eduardo Mondlane Univ. \\
\hline ORI & Okavango Research Inst. \\
\hline Lesotho & Univ. of Lesotho \\
\hline MAK & Makerere Univ. \\
\hline RU & Rhodes Univ. \\
\hline SWAZI & Univ. of Swaziland \\
\hline UCT & Univ. of Cape Town \\
\hline UDRC & Univ. of Kinshasa \\
\hline UFS & Free State Univ. \\
\hline UKZN & Univ. of KwaZulu-Natal \\
\hline UNIB & University of Botswana \\
\hline UNIZ & Univ. of Zululand \\
\hline UM & Univ. of Mauritius \\
\hline UP & Univ. of Pretoria \\
\hline USDM & Univ. of Dar esSalaam \\
\hline USB & Stellenbosch Univ. \\
\hline UWC & Univ. of WesternCape \\
\hline UZ & Univ. of Zimbabwe \\
\hline UZAM & Univ. of Zambia \\
\hline Venda & Univ. of Venda \\
\hline WITS & Univ. of the Witwatersrand \\
\hline
\end{tabular}

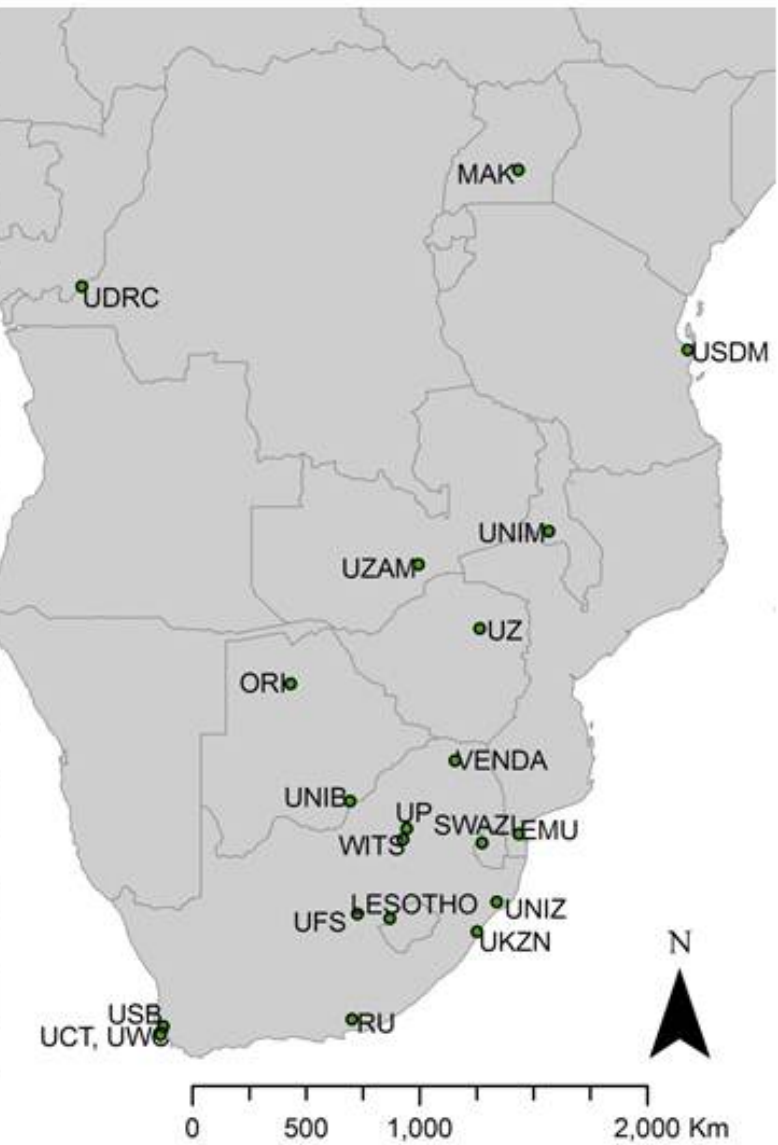

Fig. 1. Universities within continental southern Africa with some involvement in hydrological training and research (Univ. of Mauritius is not shown).

Makerere University - Fig. 1) and has an engineering department in which hydraulics, hydrology and water resources engineering forms part of the $3 \mathrm{rd}$ and 4 th year curriculum. The 4th year students are required to do a project and out of the (approximately) 100 students, some 70 frequently express a desire to do a project in the field of water and sanitation. The main problem is that they lack basic equipment (computers and laboratories, etc.) as well as sufficient staff to support both the heavy lecturing load and student project supervision. It is therefore hardly surprising that the single permanent staff member in charge of water resources engineering is not able to develop his own research programme and generate the publications required to enhance his academic profile.

Kyambogo University is by no means a unique situation and there are other institutions that have substantial potential to develop their water engineering and water science departments if some of the capacity and resource constraints are overcome. The author has discussed similar issues with young academics who are working in, or soon to return to, the universities of Botswana, Malawi (Chancellor College) and the University of Kinshasa in the Democratic Republic of Congo (Fig. 1). These all represent existing resources that are not being used to their fullest advantage for the benefit of training hydrologists and water resource engineers and scientists.

There is little doubt that many of the resources available for post-graduate training are currently funded, and were partly initiated, from outside the region. Reference has already been made to the Waternet and RISE, SSAWRN programmes, while further examples that are contributing to the development of post-graduates are CLIVET (Impacts of climate change on water resources and agriculture and adaptation strategies in Tanzania - http:// www.geus.dk/program-areas/common/int_tz03-dk.html) and NUFU (through the "Capacity building in water sciences for improved assessment and management of water resources" programme - http://espresso.siu.no/projects/ ?wicket:interface $=: 4: 1:::)$. South Africa is probably the main exception to the dominance of foreign funded students. While there are some foreign funded South African students, many more are funded through the National Research Foundation (NRF) or research projects supported by the Water Research Commission (WRC). 


\section{Main constraints}

The majority of the constraints to the further development of training and research are related in one way or another to a lack of adequate funding. While there are a number of opportunities for students to obtain funding for bursaries (and some of them can be used to study within the region), the majority of these (outside South Africa) are financed from outside the region. A large proportion of these funding opportunities do not support the development of faculty staff members within the region's university institutions and only provide limited funds for the development of research infrastructure. One of the main discussion points at research and training meetings within the region is always the low level of financial support provided by most of the national governments in sub-Saharan Africa. The inevitable result is a strong reliance on outside funding which is rarely sufficient to address the related constraints of:

- Relatively low levels of academic remuneration.

- Inadequate staffing levels.

- Inadequate access to equipment and other resources such as computers, field and laboratory equipment, textbooks and scientific journals.

- Inadequate access to updated teaching material (and not enough time available to develop them in-house).

- Inadequate support for staff research project development.

- Inadequate support for attending scientific conferences.

- Inadequate resources to develop competitive research proposals for submission to major international funding agencies.

Figure 2 presents a comparison of national expenditure on $\mathrm{R} \& \mathrm{D}$ and the size of the research community for a sample of countries around the world (Blankley and Booyens, 2010). While some countries achieve greater success in attracting people into research for the same input costs than others, it is immediately clear that South Africa does not perform very well on either count. Blankley and Booyens (2010) also noted that a substantial proportion of the South African $\mathrm{R} \& \mathrm{D}$ expenditure is derived from the private sector. Given that South Africa has a higher relative R \& D expenditure than other countries in the region, it is clear that a greater commitment is required from within the region to enable local scientists and engineers to improve their abilities to contribute to solving water related problems. It seems to be relatively easy to mobilise funds for ministerial think-tanks, the development of policy documents and inter-governmental discussion meetings on topics such as addressing the Millennium Development Goals and dealing with climate change threats. Unfortunately, it seems to be much more difficult to

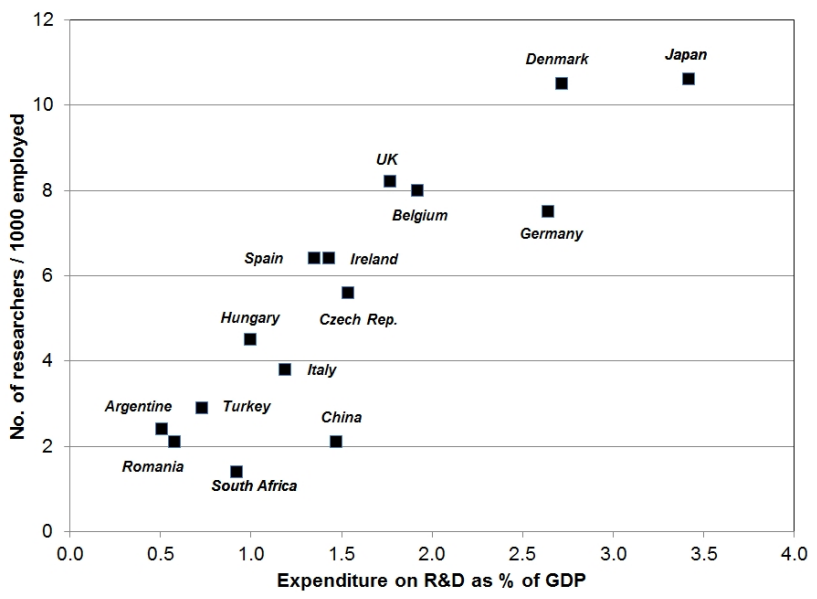

Fig. 2. Comparison of expenditure on R \& D and number of researchers (in all fields) based on 2008 data presented in Blankley and Booyens (2010).

provide local scientists and engineers with the teaching and research infrastructure necessary to find solutions to some of these problems. Is it because the governments of the region do not have sufficient confidence in their own scientists, or is it because there are too few scientists to "shout loud enough" and promote their expertise and potential value, or is it simply because there is not enough political will to support the development and implementation of locally driven solutions? In reality, the answer is probably a combination of the above plus several other disabling factors.

There are also differences within the region in terms of the number of students who are interested in pursuing careers in hydrology and water resources. Within most of the region there appears to be a plentiful source of student interest. However, within South Africa, where there are frequently more resources, it is difficult to attract students to post-graduate degree programmes and even more difficult to retain them as future research or teaching faculty members. As an example, the RISE, SSAWRN call for proposals elicited a response from South Africa of less than $6 \%$ of the total number that applied. It is frequently suggested that part of the reason for this is the perception of lower remuneration offered in academic institutions compared to other sectors requiring similar or even lower academic qualifications. This is not unique to the water sciences sector and many science departments in South African universities have reached similar conclusions. It is difficult to fully determine whether this is an accurate perception, however, on-line salary surveys (for example, www.averagesalarysurvey.com, last access: February 2012) suggest that early career professionals (4-8 yr experience) with at least a bachelors degree can expect to earn substantially more in the IT, accounting and financial, legal, business and engineering sectors than academics of a similar age group. Given that academic training includes a number of years with limited student bursary 
income, it is perhaps not surprising that academic careers are less than attractive to many young people in the region. In a listing of 64 careers covering more than 900 respondents, university professors were ranked 37th. Average salaries for all individuals with $\mathrm{MSc}$ and $\mathrm{PhD}$ degrees were listed as being 1.8 times the average for university professors (www.averagesalarysurvey.com, last access: February 2012). While the results of any salary survey are bound to be highly uncertain, depending on the profile of the respondents, there are indications that the perception of lower remuneration levels within South Africa has some foundation in reality. Attempts to locate similar information from other countries within the region were not successful. However, it has been noted that academic posts advertised for South African science faculty positions frequently attract many applicants from countries to the north, which suggests that these positions are attractive to academics in other parts of the region.

It is possible that the greater interest in post-graduate hydrology and water resources studies from countries other than South Africa is a reflection of the larger number of job opportunities in other South African sectors compared to many other sub-Saharan Africa countries. It is also possible that these differences are related to pre-university education conditions, awareness issues and other factors. While understanding these apparent regional differences could be important in terms of developing water science capacity to serve the region as a whole, there is no generally available and appropriate information that could clarify the situation.

A further constraint to the development of local postgraduate programmes is the often held perception that it is better to pursue a post-graduate degree at universities outside the region that have more elevated academic reputations. While this may be an accurate perception, it is difficult for some of the poorly resourced local universities to compete. The result is that at least some of the graduates never return to the region, although the numbers involved and the potential impact do not appear to have been quantified.

One of the constraints to improved hydrological practice is the lack of capacity of local water resources managers (mostly employed as civil servants) to adopt new approaches. This means that even locally developed and applied research products are rarely used and there is a shortcircuit in the processes associated with translating research into practice, evaluating the benefits and generating further research to continually improve both scientific understanding and practical applications. While there are some regional institutional arrangements for linking research to policy and applications, their effectiveness in terms of implementation (rather than policy development) is questionable. For example, the SADC (Southern African Development Community) accepted a report funded by the Water Research Commission of South Africa (SADC, 2001) that provided a detailed terms of reference for a project designed to quantify the surface water resources of southern Africa in an integrated manner.
While the report explicitly addressed one of the SADC Water Sector regional strategic action plans there were no follow up actions and the assessment of water resources in the SADC region continues to be based on regionally fragmented approaches. Gustard (2002) refers to the need for a greater emphasis to be given to the process of technology transfer, follow-up research and training in the use of appropriate software tools. While problems of transferring science into practice are certainly not unique to the developing countries of the world, the gap is arguably wider in developing countries due, in part, to communication problems between those involved in research, practice, management and policy development, as well as a lack of resources to effect real changes.

The final bullet point at the beginning of this section refers to the resources required to develop competitive research proposals to international funding agencies. A further issue is that the structure of many of the funding calls often fosters north-south cooperation (e.g. between European or North American and sub-Saharan Africa institutions), but rarely fosters south-south cooperation. Many sub-Saharan university departments or research institutes do not have the resources, or administrative support, to navigate the complex procedures required to submit proposals to (for example) the European Union, and are therefore highly reliant upon their more experienced European or North American partners. The result is that many institutions in sub-Saharan Africa are aligned with partners from outside the region and find themselves competing against other institutions within the region. While competition for funding is not unique to the sub-Saharan Africa region and is a necessary part of allocating research funds, the lack of resources prevalent in many of the region's institutions puts them at a serious disadvantage.

The overall result of these constraints is that all of the resources (including human, financial and materials) required to further develop teaching, training and research in hydrology and water resources science are severely limited and there is a real fear that even the current situation is unlikely to be sustainable. The retirement of key individuals has the potential to cause the collapse of an institution's research and post-graduate teaching programme if there are no suitably trained and experienced persons to replace them. A further problem is that the termination of one or more foreign funding programmes can result in a substantial decrease in the number of post-graduate study opportunities - something that the region can ill afford, given the relatively small number that are currently available. Just as it appears to be very difficult for many of the countries of sub-Saharan Africa to emerge from the real (socio-economic) poverty gap, so it is equally difficult for them to emerge from the "research" poverty gap.

An analysis of the results of a SCOPUS (http:// 0-www.scopus.com.wam.seals.ac.za/home.url, last access: 14 February 2012) search using "hydrology and Africa" in document titles, abstracts and keywords revealed that the 
majority of the contributions have been made from outside the region. A total of 804 authors are listed in the search results, 468 of them having contributed 5 or more publications. $76 \%$ of the authors with greater than 5 "hits" are affiliated with institutions based outside the region (dominated by France, UK, Netherlands, Denmark and USA), while $68 \%$ of the remainder are affiliated with South African institutions. The picture does not change very much if all the authors are included (79\% outside the region and the remainder still slightly dominated by South Africa). While there are many different ways in which publication databases can be analysed, it is abundantly clear that scientific contributions to hydrology in Africa do not primarily originate from African institutions.

\section{The way forward}

While the previous section has painted a somewhat gloomy picture of the situation in the region, there has been significant progress in recent years that has resulted in more research activity, specifically at the post-graduate level. The example of the success of WaterNet (Jonker et al., 2012) has already been referred to, and while primarily focused on MSc level training has generated a large number of students who are more than academically prepared to take on the challenges of a $\mathrm{PhD}$ research programme. The Carnegie funded RISE project (http://sig.ias.edu/rise), that is supporting more than $20 \mathrm{PhD}$ and MSc students from some 10 countries in Sub-Saharan Africa through the SSAWRN, has also been referred to. A more recent example comes from the Ethiopian Institute of Water Resources (EIWR), launched in 2011, which has enrolled $18 \mathrm{PhD}$ and $24 \mathrm{MSc}$ students working on projects related mainly to drinking water, food security and hydroelectric energy (A. Viglione, personal communication, 2012). From the perspective of the development of scientific hydrology in the region, it is perhaps unfortunate that the focus of many of these student projects is on water resources management issues. However, the author also recognizes that this is perhaps inevitable and appropriate in a region where there are many water management problems that require urgent solutions.

The critical issue is therefore to find ways in which this progress can be sustained as well as removing some of the barriers that might be preventing even greater progress. There needs to be a concerted effort to pool the available resources and encourage the development of a critical mass (of facilities, human capacity and financial resources) that will contribute to a sustainable future. Given the overall socio-economic status of the countries in the region, and the fact that this seems unlikely to improve substantially in the near future, it will always be necessary to rely to a certain extent on support from outside the region. This issue has been recognized by many groups including the African Renaissance Institute of Science and Technology (ARIST - http://www.arist-edu.org/) whose objective is "to foster the transformation of Africa through education, research, innovation, entrepreneurship, and community outreach". The real issue is therefore how can outside assistance be used to effectively develop sustainable local capacity? The ultimate objective must be to create a situation where African water science and engineering groups can compete or collaborate on equal terms with their colleagues from more developed countries. What should be avoided is some type of scientific colonialism, where the outside organizations remain the dominant force.

There are many instances where major development projects in the region are undertaken by outside (the region) consulting companies, sometimes with local partners and a training component, but quite frequently without. Some organisations in the region have referred to the lack of followup activities once the initial training of local partners has taken place. This type of approach rarely develops effective capacity in research or practice within locally based institutions. Part of the reason for favouring outside consultants may be related to the lack of available local expertise, or the lack of awareness of the existence of local expertise and the lack of capacity of local qualified staff to bid for such contracts. The problem could also be related to assumptions by politicians that experts from developed countries are more skilled and can provide better solutions than local scientists and engineers.

There is little doubt that networks of potential collaborators in research, training or practice are not fully integrated in sub-Saharan Africa. While there are a number of different collaborating groups (collaborating with each other and with organisations outside the region), they are often not very extensive, tend to be rather exclusive and often compete for funding opportunities with each other. WaterNet (Jonker et al., 2012) represents an exception to this situation, is designed to be more inclusive and has played a major networking role in recent years. However, there remain other groups that are not part of existing areas of cooperation and appear to experience difficulties in "breaking in". While the concepts behind establishing "centres of excellence" (not necessarily located in a single geographic location) may be sound, in practice they tend to favour those institutions that already have capacity at the expense of those that do not. This situation tends to be counter-productive when it comes to developing the capacity in the region as a whole. It is inevitable that there will always be some groups that have experience of working successfully together and these should be encouraged to continue. However, there appears to be a need for a broader, non-aligned "umbrella" network that can support established groups as well as encourage the development of emerging groups. The intention of such an umbrella network would not be to exercise control and add any additional administrative burden, but to add real value to existing initiatives in an attempt to ensure their sustainability and to make them more inclusive. An umbrella 
network approach might also be used to revive previous initiatives that were productive in the past but have recently become largely inactive. An example is the UNESCO Southern Africa FRIEND (Flow Regimes from International Experimental Network Data) programme that generated valuable regional research results during a $10 \mathrm{yr}$ period up to 2003 (UNESCO, 1997, 2004), but has been largely inactive since then, partly due to a lack of funding and partly due to the original partners becoming involved with other projects and not having the resources to contribute to both.

Lack of access to and awareness of research and teaching material is often quoted as being a stumbling block for research and developing new teaching programmes. This material includes textbooks, or other source material for lectures, journals and some of the global datasets that research organisations in other parts of the world take for granted. It is therefore encouraging that there are several existing and planned initiatives to improve the access to the material available for under-resourced universities in developing countries. One such programme is Research4Life (www.research4life.org), which is aimed at reducing the knowledge gap by providing affordable access to critical published scientific research. In a similar vein, the International Association of Hydrological Sciences (IAHS) initiated the Task Force for Developing Countries (TFDC) some years ago. This programme distributes IAHS publications free of charge to universities all over the developing world, including some 28 in Africa.

With respect to teaching resources, a US team of hydrology educators have recently initiated MOCHA (Modular Curriculum for Hydrological Advancement - www.mocha. psu.edu), designed to share the development of teaching material created by a range of experts in specific fields of hydrology. This type of resource could become invaluable to university departments in the sub-Saharan Africa region, particularly if some experienced lecturers can contribute material that has a strong local flavour and relevance. Similarly, a web-based portal of global and regional datasets (Watershed and Hydrologic Information Portal - WHIP) is under development by the University of Washington and others. This web portal will include links to data sources, the ability to search or filter by data type and region, primary references describing each dataset, guidelines on use of the data (inferences that can be made), and examples of how to use the data from published literature. It is, however, important to recognize that many sub-Saharan African universities still do not have adequately reliable and fast internet connections to be able to make the best use of web-based resources.

\section{Conclusions}

A large part of the content of this contribution is based on the personal experience of the author combined with inputs of the opinions of others gleaned from discussions at conferences, workshops and other meetings. Many of the opinions are difficult to support with hard facts as much of the information is not formally documented. There is therefore a need to canvas the opinions and attitudes of a broader community of role players (students, academics at different career levels, practitioners, managers) from both within the region and outside. The purpose of such a survey would be to obtain more explicit information that can be used to re-analyse some of the issues raised in this paper, arrive at some more definitive conclusions and provide a basis for the future planning of training and research needs. This survey could be conducted under the auspices of the IAHS working group on hydrology education and use existing networks (such as WaterNet) to contact a broad and representative audience.

Despite the current lack of information there are recurrent themes that emerge during discussions with hydrological scientists and water engineers who work within the region. These are related to a lack of financial resources and a feeling of being trapped in a "research" poverty gap that many individuals and institutions find difficult to emerge from. Table 1 summarises many of the constraints (and some of the reasons for their existence) and possible solutions that have been referred to in the sections above. There are overlaps amongst both the constraints and the possible solutions and it is apparent that many of them are related to funding.

The statement made above that the region has a small pool of qualified scientists may seem to be incompatible with some of the recent developments in training and outputs of post-graduate students. However, it appears to be difficult to attract these emerging scientists into academic (research and training) posts; an essential requirement if the existing training initiatives are to be sustained. There are several possible reasons for this situation, including a relatively small number of available academic posts and uncompetitive remuneration packages (especially for early career academics). While some research positions are available, they are often based on short-term contracts that offer little in terms of job security. While academic career prospects for young scientists are somewhat limited, it is also becoming increasingly difficult to develop academic staff succession plans and the age profile of existing faculty staff is becoming dangerously high.

While there is clearly a need to develop interdisciplinary research approaches to solving complex water resources issues, this should not be achieved at the expense of sound training in the individual disciplines (Metzger and Zare, 1999). Recent trends that focus on training in the broad issues of water resources management (through course-work MSc programmes and short courses for professionals) should not be seen as a substitute for training in scientific research, which is less than adequately developed in the region. Both are important and have roles to play in the further development of water-related skills in the region. However, the former tend to be more attractive to both funders and students as they offer promises of training in "work-related" skills. This is quite an important selling point in a region 
Table 1. Summary of current constraints and possible ways forward (note that there will be overlaps between the constraints and solutions).

\begin{tabular}{|c|c|}
\hline Current constraint or situation (and reasons) & Possible solutions \\
\hline $\begin{array}{l}\text { Not enough faculty members to sustain training } \\
\text { and research (poor remuneration and lack of } \\
\text { facilities). }\end{array}$ & $\begin{array}{l}\text { Improved facilities and remuneration. } \\
\text { Active recruitment drive, particularly of } \\
\text { younger academics. }\end{array}$ \\
\hline $\begin{array}{l}\text { Too much reliance on foreign funding (not } \\
\text { enough R \& D funding commitment from } \\
\text { governments in the region). }\end{array}$ & $\begin{array}{l}\text { Demonstrate the value of science } \\
\text { training and research to national } \\
\text { governments and lobby for additional } \\
\text { local funding. }\end{array}$ \\
\hline $\begin{array}{l}\text { Not enough basic hydrological science } \\
\text { education (lack of resources and staff. } \\
\text { Over-emphasis on water management). }\end{array}$ & $\begin{array}{l}\text { Focus staff recruitment and educational } \\
\text { resource development on science. } \\
\text { Improve access to developing } \\
\text { international teaching and research } \\
\text { resources. }\end{array}$ \\
\hline $\begin{array}{l}\text { Focus on training in existing solutions to } \\
\text { problems (lack of resources to switch to new } \\
\text { approaches or lack of awareness of new } \\
\text { approaches). }\end{array}$ & $\begin{array}{l}\text { Focus on emerging problems as well as } \\
\text { new approaches to their solution. }\end{array}$ \\
\hline $\begin{array}{l}\text { Lack of access to, or awareness } \\
\text { of existing research resources. }\end{array}$ & $\begin{array}{l}\text { Need demonstration projects to illustrate } \\
\text { the use and value of such as Earth } \\
\text { Observation (EO) data and existing } \\
\text { hydrological modeling software systems. }\end{array}$ \\
\hline $\begin{array}{l}\text { Not enough integration of science and practice } \\
\text { (lack of communication and commitment). }\end{array}$ & $\begin{array}{l}\text { Improve communication between } \\
\text { scientists, practitioners and managers } \\
\text { within the region. Encourage water } \\
\text { managers to use research outputs from } \\
\text { the region. }\end{array}$ \\
\hline $\begin{array}{l}\text { Too little understanding of interdisciplinary } \\
\text { approaches (separation of disciplines). }\end{array}$ & $\begin{array}{l}\text { Encourage interdisciplinary research and } \\
\text { teaching, but not at the expense of } \\
\text { adequate training in single disciplines. }\end{array}$ \\
\hline $\begin{array}{l}\text { Lack of integration of small research groups } \\
\text { (lack of adequate networking). }\end{array}$ & $\begin{array}{l}\text { Encourage the development of an } \\
\text { "umbrella" network that can support } \\
\text { existing and new research groups. }\end{array}$ \\
\hline $\begin{array}{l}\text { Poor integration of local research with } \\
\text { international research (lack of access to, or } \\
\text { awareness of international research } \\
\text { programmes and funding). }\end{array}$ & $\begin{array}{l}\text { Encourage network links between local and } \\
\text { foreign groups (or individuals). Improve } \\
\text { training in the development of research } \\
\text { proposals. }\end{array}$ \\
\hline
\end{tabular}

where potential employment opportunities are a high priority. It is therefore important to establish an improved balance between science and practice when looking at future possible developments in training and education. The addition of more science training could be used to support some of the existing programmes that focus on the integration of skills and their application in practice. Part of the training and research should include the concepts and methods that can be used to deal with uncertainty in science and practice, which represents a paradigm shift for most countries in the world (Wagener et al., 2010) and not only the sub-Saharan Africa region. These concepts should be applied to the individual disciplines (hydrology in particular), as well as to the cross-disciplinary links that should ultimately contribute to improved water resources management.

From a more optimistic perspective, there have been a number of positive trends (notably WaterNet, SSAWRN and more recently the Ethiopian EIWR initiative) that have resulted in the completion of some sound scientific research and the development of the careers of a number of locally based academics and practitioners (e.g. Kapangaziwiri, 2011; Kongo, 2008). While these are encouraging trends, the conclusion of this paper is that a "critical mass" has not been reached and the current system is too heavily dependent on outside support (financial and in terms of supervisory expertise) to be considered sustainable in the long-term. This 
comment is not meant to imply that foreign funding is a problem, but that a better balance between foreign funding and local investment in water education and research should be encouraged. It is suggested that the sub-Saharan African community of water resource scientists and engineers involved in education and research need to establish improved networks in which they can share inter alia expertise, research resources (models, software, data sets, etc.), information about locally and globally available data as well as contacts with potential research partners and funders, within and outside the region. Many institutions are not even aware of the existence of others, or are not familiar with their expertise or potential to contribute to collaborative research projects. Improved networking could help to solve some of these problems and could even contribute to mobilizing the community to get its voice heard in the government departments of the region that control the education, research and development budgets. WaterNet (Jonker et al., 2012) has achieved a great deal and provides a sound basis upon which to build a future approach to networking.

Perhaps one of the critical questions to be asked is how international organisations and existing structures, such as UNESCO, IAHS, WaterNet and RISE (SSAWRN) can contribute to resolving some of the constraints and further encourage the development of hydrology teaching and research in sub-Saharan Africa? There is no doubt that contributions are already being made and some further suggestions have been made within this paper, but it is important to determine what else needs to be done to try and establish the critical mass in hydrology research and bridge the research poverty gap.

Acknowledgements. I am grateful to a number of students and young academics at various universities within sub-Saharan Africa who have provided me with information about the current situation within their institutions. Notably I would like to thank Elonio Miuiane from Eduardo Mondlane University in Maputo, Isaac Mutenyo from Kyambogo University in Kampala, Raphael Tshimanga from the Democratic Republic of Congo (currently a PhD student in the IWR at Rhodes University), Piet Kenabatho at the University of Botswana and Graham Jewitt from the University of KwaZulu-Natal, South Africa. I am also grateful for the opinions expressed by several academics from outside the region, who are actively engaged in developing scientific capacity within sub-Saharan Africa, but who work outside the region. This includes Lena Tallaksen of the University of Oslo (Norway), Karen Vilholth and Simon Stisen of GEUS (Denmark) and Thorsten Wagener of Pennsylvania State University (US), who also provided some very valuable comments on a preliminary version of this paper. Alberto Viglione of the Institute of Hydraulic Engineering and Water Resources Management of the Vienna University of Technology provided the information on the Ethiopian Institute of Water Resources.

Edited by: T. Wagener

\section{References}

Andersson, L., Wilk, J., Todd, M. C., Hughes, D. A., Earle, A., Kniveton, D., Layberry, R., and Savenije, H. H. G.: Impact of climate change and development scenarios on flow patterns in the Okavango River, J. Hydrol., 331, 43-57, 2006.

Blankley, W. O. and Booyens, I.: Building a knowledge economy in South Africa, S. Afr. J. Sci., 106, 6 pp. doi:10.4102/sajs.v106i11/12.373, 2010.

Grey, D. and Sadoff, C.: Water Resources and Poverty in Africa: Breaking the Vicious Circle. Paper Presented to the African Ministerial Conference on Water, Abuja, Nigeria, available at: www. africanwater.org/Documents/amcow_wb_speech.pdf, 2002.

Gustard, A.: FRIEND: an international network for bridging the gap between research and practice. FRIEND 2002 - Regional Hydrology: Bridging the Gap between Research and Practice. Proceedings of the 4th International Conference on FRIEND held in Cape Town, South Africa, March 2002, IAHS-AISH P., 274, 3-10, 2002.

Hughes, D. A.: Water resources estimation in less developed regions - issues of uncertainty associated with a lack of data. Prediction in Ungauged Basins: Promises and Progress (Proceedings of symposium S7 held during the Seventh IAHS Scientific Assembly at Foz do Iguaçu, Brazil, April 2005), IAHS-AISH P., 303, 72-79, 2006.

Hughes, D. A.: Hydrological models: mathematics or science?, Hydrol. Process., 24, 2199-2201, 2010.

Hughes, D. A., Kapangaziwiri, E., and Sawunyama, T.: Hydrological model uncertainty assessment in southern Africa, J. Hydrol., 387, 221-232, 2010.

Jonker, L., van der Zaag, P., Gumbo, B., Rockström, J., Love, D., and Savenije, H. H. G.: A regional and multi-faceted approach to post-graduate water education - the WaterNet experience in Southern Africa, Hydrol. Earth Syst. Sci. Discuss., in press, 2012.

Kapangaziwiri, E.: Regional application of the Pitman monthly rainfall-runoff model in southern Africa incorporating uncertainty, unpublished $\mathrm{PhD}$ thesis, Rhodes University, South Africa, 2011.

Kapangaziwiri, E., Hughes, D. A., and Wagener, T.: Towards the development of a consistent uncertainty framework for hydrological predictions in South Africa. New approaches to hydrological prediction in data sparse regions (Proc. symposium HS2 at the joint IAHS \& IAH convention, Hyderabad, India, September 2009), IAHS-AISH P., 333, 84-93, 2009.

Kirchner, J. W.: Getting the right answers for the right reasons: Linking measurements, analyses and models to advance the science of hydrology, Water Resour. Res., 42, W03S04, doi:10.1029/2005WR004362, 2006.

Kirshen, P. H., Vogel, R. M., and Rogers, B. L.: Challenges in Graduate Education in Integrated Water Resources Management, J. Water Res. Pl.-ASCE, 130, 185-186, 2004.

Kongo, V. M.: Balancing water for food and environment: hydrological determinants across scales in the Thukela River Basin, unpublished $\mathrm{PhD}$ thesis, University of KwaZulu-Natal, South Africa, 2008.

Lumsden T. G., Schulze, R. E., and Hewitson, B. C.: Evaluation of potential changes in hydrologically relevant statistics of rainfall in Southern Africa under conditions of climate change, Water SA, 35, 649-656, 2009. 
Metzger, N. and Zare, R. N.: Interdisciplinary Research: From Belief to Reality, Science, 283, 642-643, 1999.

Muzik, I.: Post-graduate education in Hydrology today and future needs, in: Past, Present and Future of Post-graduate Education in Hydrology, edited by: Salz, H., IHP-V, Technical Documents in Hydrology No. 4, UNESCO, Paris, 169-175, 1996.

Nash, J. E., Eagleson, P. S., Phillip, J. R., and Van der Molen, W. H.: The education of hydrologists, Hydrolog. Sci. J., 35, 597607, 1990.

Pappenberger, F. and Beven, K.: Ignorance is bliss: Or seven reasons not to use uncertainty analysis, Water Resour. Res., 42, W05302, doi:10.1029/2005WR004820, 2006.

SADC: Assessment of surface water resources. Regional Strategic Action Plan for Integrated Water Resource Development and Management. Southern African Development Community, Water Sector Co-ordinating Unit, 2001.

Salz, H. (Ed.): Past, Present and Future of Post-graduate Education in Hydrology. IHP-V, Technical Documents in Hydrology No. 4, UNESCO, Paris, 1996.

UNEP: “Africa Water Atlas". Division of Early Warning and Assessment (DEWA). United Nations Environment Programme (UNEP), Nairobi, Kenya, 2010.

UNESCO: Southern African FRIEND, Technical Documents in Hydrology No. 15, UNESCO, Paris, 1997.
UNESCO: Southern African FRIEND Phase II 2000-2003, Technical Documents in Hydrology No. 69, UNESCO, Paris, 2004.

Vörösmarty, C. J., Green, P., Salisbury, J., and Lammers, R. B.: Global water resources: Vulnerability from climate change and population growth, Science, 289, 284-288, 2000.

Wagener, T., Weiler, M., McGlynn, B., Gooseff, M., Meixner, T., Marshall, L., McGuire, K., and McHale, M.: Taking the pulse of hydrology education, Hydrol. Process., 21, 1789-1782, 2007.

Wagener, T., Sivapalan, M., Troch, P. A., McGlynn, B. L., Harman, C. J., Gupta, H. V., Kumar, P., Suresh, C. R., Basu, N. B., and Wilson, J. S.: The future of hydrology: An evolving scinence for a changing world, Water Resour. Res., 46, WO5301, doi:10.1029/2009WR008906, 2010.

Wright, E. A., Savenije, H. H. G, and van der Zaag, P.: The development of a collaborative Master degree program in integrated water resources management in Southern and Eastern Africa, Proceedings of the 7th Annual International Conference on Engineering Education "Progress through Partnership - Strengthening Alliances", Oslo, 7D7-13-18, 2001.

Yadav, M., Wagener, T., Gupta, H. V.: Regionalisation of constraints on expected watershed response behaviour, Adv. Water Resour., 30, 1756-1774, 2007. 